\title{
Anna Pluskota-Lewandowska
}

\section{Lifelong Learning for Inclusion - between Theory and Practice}

\begin{abstract}
In this study I present the conclusions of reports of the research teams which examined the policy range and analysed the activities regarding the inclusion of the socially deprived in rural areas, i.e. the British, Hungarian and Polish reports. When undertaking to find a reply to the question raised at the beginning of this article, I considered that the empirical basis would be quality material collected within the framework of focused group interviews ${ }^{1}$.

Although the focused group interviews were conducted according to a scenario which was prepared by the research teams, changes were possible in each country (although these changes did not affect the research issue). Apart from the main aim of the discussion, i.e. the diagnosis and analysis of both successes and failures of educational activity enabling social inclusion, these differences concerned the digressions concentrating on poverty and social exclusion in rural areas and problems connected with the implementation of inclusive policy - Hungary; considerations concerning the kind of help which should be provided to individuals and groups struggling with poverty in the countryside - Great Britain; methods evaluating the effectiveness of aid agencies acting in favour of social inclusion - Poland.

Representatives of government agencies playing a key role in the introduction of various forms of inclusive policy and representatives of institutions which provide

1 The empirical material gathered both from in-depth individual interviews and a diagnostic survey is insufficient for the analysis the aim of which is an attempt to answer the question about the effectiveness of social inclusion through lifelong learning. Electronic survey data show that according to the majority of interviewed representatives of aid institutions, educational services provided to those at risk of marginalisation and socially excluded, achieve expected results, end successfully, since the beneficiaries of these services find employment on the local labour market.
\end{abstract}


direct help to the marginalised and those exposed to social marginalisation (which use various educational methods) took part in the research.

Keywords: lifelong learning, adult education, inclusion, marginalisation, rural areas, aid programmes, youth.

\section{Introduction}

Lifelong learning is one of the priorities of EU inclusive policy. It seems that this rather old yet rediscovered idea is considered as a remedy for marginalisation and social exclusion. It engages substantial financial and human resources in projects and programmes assuming social inclusion while using the possibilities provided by lifelong education. Attention should be given to the problems and limitations (diagnosis and an indication of their sources) connected with the implementation of inclusive policy based on assumed possibilities, lifelong learning and teaching potential. This is a question about the relationship between theory, a meticulous action plan and practice. This article takes a close look at that relationship, its basis being the findings collected within the framework of the international research programme The impact of Lifelong Learning policies on the inclusion of vulnerable groups DG Employment, Social Affairs and Equal Opportunities; Project Agreement Number: VS/2005/0688. The aim of the programme was an evaluation of the influences of lifelong education on the integration of the marginalised and the prevention of the social exclusion of groups at risk. The programme lasted from December 2005 until February 2007. Eight research teams took part in it from Great Britain, Denmark, Greece, Hungary, Germany, Sweden, Spain and Poland ${ }^{2}$. The research teams in Denmark, Greece, Germany, Sweden and Spain agreed that immigrants are most exposed to exclusion and social marginalisation. Hence the evaluation of inclusive policy conducted on the basis of lifelong learning which was undertaken by the research teams in the mentioned countries, involved this social category (the target group). Whereas the researchers responsible for running the programme in Great

2 The Polish research team included: Dr. Grzegorz Zabłocki, professor at Nicolaus Copernicus University, Toruń, Dr. Anna Pluskota-Lewandowska - Institute of Sociology, NCU and Dr. Jolanta Maciąg who works in association with the Institute. 
Britain, Hungary and Poland showed that disadvantaged rural communities are particularly exposed to exclusion and marginalisation. In Great Britain this category included poorly educated and poorly qualified young people, in Hungary it included the unemployed whereas in Poland the young unemployed in post- state farm areas.

An audit of the National Action Plan for Social Integration was conducted within the framework of this programme in all the above mentioned countries. Electronic surveys were sent to institutions responsible for support in obtaining financial and social independence for those without it ${ }^{3}$. Delivery agencies and implementation agencies which specialise in helping target groups through education, consultancy, information, organisation of apprenticeship and training were selected for the research. The next step was the organisation of focused group interviews with representatives of institutions which were of interest to us and carrying out in-depth individual interviews with key persons responsible for the creation of inclusive policy in the already mentioned countries.

\section{Lifelong Learning - Its Significance}

Given the multitude of ways of understanding this topic and while being aware of the problems which its broad definition may create, we agreed that lifelong learning means all learning activity undertaken throughout life, with the aim of improving knowledge, skills and competence, within a personal, civic, social and/or employment-related perspective $e^{4}$. It was agreed that lifelong learning involves all its accessible forms - formal, informal and incidental education. It was interesting to take a closer look at how lifelong learning (LLL) is understood by FGI participants. The LLL concept has a similar definition in all the countries participating in the research with differences in some aspects. In Great Britain respondents underlined the significance of formal education in LLL, particularly in the context of marginalised groups and the excluded in rural areas or those exposed to such danger. In Hungary all forms of learning

${ }^{3}$ Further in the text when describing institutions responsible for obtaining financial and social independence for people who do not have it, I simply use the word 'institutions'.

${ }_{4}$ This understanding of lifelong learning is identical to the European Commission definition - Europe, 2003. 
after the completion of formal education were emphasised, that was also the case in Poland where the respondents highlighted adult education ${ }^{5}$.

Respondents in all the countries underlined that while investigating the opportunities provided by lifelong learning in the process of social inclusion in rural areas significant social issues which involve social exclusion, requiring a coordinated approach with other aid mechanisms cannot be overlooked. Despite the fact that a low standard of education and poor qualifications were considered the main reason for marginalisation and social exclusion in rural areas, those taking part in the research believe that professional aptitude does not guarantee entrance to the labour market.

\section{Perceiving the Educational Effectiveness of Aid Activities}

In order to try and answer the question being at the core of carrying out FGI, we also asked the participants about the successes and failures of aid activities undertaken in the name of inclusion. We were interested to know how the researched representatives of institutions evaluate the effectiveness of their activities aimed at clients. It appears from the research that the majority of those researched highly value the activities of institutions represented by them. Representatives from Great Britain are particularly good at this, pointing to such successes like employer engagement enabling learning to take place at employers' premises and at times suitable for people working shifts, number of adults gaining levels $1 \& 2$ Adult Literacy and Numeracy Certificates. The Polish and Hungarian interviewees also perceived their own activity in categories of success rather than failure - the basis for evaluations was firstly that the researched institutions helped the young unemployed find work. Taking into consideration the interviewees' earlier responses about the fact that providing professional skills to the underprivileged inhabitants of rural areas does not guarantee entrance to the labour market, their trust in the strength and legitimacy of the institutions represented by them is rather surprising. The majority of respondents believe in the effectiveness of the educational activity undertaken by them. However, this fact can be interpreted as a functional 'defence' of the principle organising the existence and activity

${ }^{5}$ In Polish academic literature the lifelong learning issue is often incorrectly identified with adult education. Hence the Polish respondents' tendency to interpret adult education as an equivalent of lifelong learning. 
of aid institutions ${ }^{6}$. This belief does not exclude the articulation of issues restricting activity to which the respondents devoted considerable attention during the discussion. Let us, therefore, take a look at the issues which were raised.

\section{Problems Restricting Educational Aid Activity}

I decided to classify the difficulties mentioned by the respondents so as to give a structure to the decisions made in this part of the study. The problems hindering aid activity based on lifelong learning are based on three basic issues connected with:

- The specificity of projects and aid programmes,

- The specificity of activity,

- The specificity of the clients (aid receivers).

Problems connected with the specificity (construction) of projects and aid programmes concern difficulties resulting from the structure, principles of financing the programmes, administrative restrictions - bureaucracy, lack of coherent inclusive policy, short-term programmes and low flexibility, as well as the very nature of the projects and programmes using lifelong learning generally understood as providing basic professional qualifications to adults, for whom social inclusion is to take place.

The obstacles which I classified as being specific for aid activity refer to the lack of cooperation between institutions (delivery and implementation agencies), programme centralisation, the nature of the rural labour market, omitting clients' views. The limitations based on the specificity of clients of researched institutions are the difficulties in reaching the aid receivers, finding out about their needs due to their low or totally non-existing awareness, low motivation of clients to be taught and thus included into the main stream of social life. I now intend to clarify the above mentioned problems ${ }^{7}$.

6 This theme will be developed later in this article.

7 Fouli Papageorgiu analyses the results of research presented in this article in a slightly different manner. She concludes that the sources of both successes and failures of inclusive policy conducted on the basis of lifelong learning should be sought among factors functioning on three levels: at policy formulation and policy management level, at service provision level, at vulnerable group (client) level. (Papageorgiu, F. (2008: 65-67). 


\subsection{Problems Connected with the Specificity of Projects and Aid Programmes}

The difficulties emerging from the structure of financing programmes restrict the activity of the analysed institutions. These issues were given particular attention by participants in the discussion in Hungary and Poland. The biggest problem is for the institutions which are bound by agreement with the sponsor of financial resources for a given programme to maintain financial stability, they are expected to commence activity without having funds for its realisation. Those undergoing the research underline that priority is given to large, wealthy institutions able to afford the pre-financing of projects. The consequences of this fact are predictable - aid institutions functioning in rural areas are usually small organisations with limited human and financial resources which cannot afford the pre-financing of their own activity. This means less dynamic educational activity of aid institutions directed at the rural population, (particularly in areas situated at a fair distance from towns) limited in both quantity and quality in comparison with urban areas.

In Great Britain inclusive policy conducted on the basis of lifelong learning concentrates on providing marginalised individuals with basic education and professional qualifications - the lack or low level of which among rural inhabitants was diagnosed by the government of Great Britain as the most urgent problem in rural areas. Therefore, financial priority is given to those projects which are orientated towards education and qualifications. Inclusive policy carried out along such priorities did not bring the expected results in Great Britain - despite carrying out many educational initiatives over the past fifteen years it is hard to talk of the nation's particular educational achievements in this context ${ }^{8}$.

This kind of inclusive policy which is also characteristic for Hungary and Poland raises many doubts. Such as the assumption that the excluded and threatened with exclusion should be provided with professional skills which will allow them to find employment. Firstly, social exclusion is a complex phenomenon, unemployment being one of its symptoms. Although finding a permanentjob does indeed improve the excluded person's financial conditions, it does not necessarily lead to entire inclusion in social life. Employment -

8 This fact was emphasised by representatives of aid institutions from Great Britain taking part in the discussion. 
security, improvement of financial conditions may lead to a growth in client consumption at given institutions. And nothing other than that. Hence the idea that finding employment means social inclusion is deceptive. Secondly, the interviewees in all the countries did have reservations which should not be overlooked - that teaching clients the basic educational and professional skills is not a guarantee for entering the labour market where expectations for those skills and qualifications are dwindling.

Thirdly, an educational offer defined and designed in such a manner (from above, without the participation of the interested party) tends to be unattractive to the recipients who perceive its inadequacy in relation to the dynamically changing labour market and to their own expectations.

Fourthly, attention must be given to the fact that being provided with basic professional skills may bring results which are the reversal of the initial aim - it may reinforce marginalisation and social exclusion in rural areas. What I have in mind is 'pushing' individuals who are marginalised, excluded or exposed to exclusion into narrow, limited, development trajectories. The consequence of this is, in the best case, allocating them to lower social positions than the privileged. However, on the changing labour market which is neither big nor saturated in rural areas, possessing basic skills and qualifications which were acquired during short courses and training may be a significant drawback. As I have already mentioned, these skills and qualifications are less and less useful - their demand is dwindling.

The consequence of lack of financial continuity are programmes designed for the short term which do not guarantee balanced, long-term and effective aid activities. Acquiring professional competence in a short time is debatable, not only for reasons of durability and usefulness but also due to the difficulty in evaluating the effectiveness of the educational process which was designed as being short-term. How can it be unequivocally stated, that the activity (conducted over a short period of time) leads to the social integration of the marginalised or exposed to marginalisation? It is not easy to measure the effect of a concrete activity on a given phenomenon, having to deal with a multitude of various influences which can significantly intervene in the process of inclusion or social exclusion. Perhaps many other factors which were not taken into account during the research had an influence on this fact. It is therefore, very difficult to state whether acquiring skills, professional qualifications (acquired during short courses) which enabled getting employment, led to inclusion. 
The respondents complained about the restrictions resulting in administrative structure and the structure of managing programmes which are considered as over complicated. In their opinion the rules of projects and programmes, particularly those financed by the EU are very complex, change every year, which means having to involve financial and human resources for something which is not directly connected with the set goals. This is particularly restrictive for small aid institutions connected with rural areas. According to respondents in all the countries, the programmes can only be successful if they are flexible, adaptable to local conditions (social, economic) and the specific requirements of target groups. Taking into account the responses of interviewees, it can be concluded that room for manoeuvre is very limited - projects and programmes are seen as being inflexible. Changes which would include not only multidimensional social exclusion but also all regional, local, ethnic or even geographically varied differences (mentioned by the Hungarian respondents) can rarely be implemented.

A significant difficulty in inclusive activity using lifelong learning is inconsistent integration policy. It is difficult to function within its framework particularly for institutions in Poland and Hungary. Respondents from Great Britain also complained about the inconsistency of the policy but to a far lesser degree. The lack of agreement at the highest, decisive level and frequent conflicts between government administration departments, the poorly defined division of responsibilities between them, leads to the lack of holistic and coordinated integration strategy.

\subsection{Problems Connected with the Specificity of Aid Activities in Institutions}

As I have already mentioned, a consequence of the lack of a coherent, holistic and coordinating integration policy are the difficulties emerging at implementation level - in rural areas many initiatives are scattered and disconnected. Aid institutions rarely cooperate with one another (which is not surprising given the competitive nature of the projects) and rarely share experience and information. The problem is not only poor cooperation between the delivery agencies, providing help to the marginalised, the excluded and exposed to exclusion but also limited cooperation between implementation and delivery.

While examining the question of cooperation the involvement of 'local resources', i.e. individuals and institutions should also be considered. This 
type of cooperation is particularly significant in the context of low social trust (particularly in Poland and Hungary) ${ }^{9}$. By involving those 'local resources' into their own activity, external aid agencies become less alien, more credible, gain acceptance, thereby increasing opportunities of effectiveness. Analysing the respondents' statements shows that the 'local resources' potential is hardly used - this deficit was mentioned by both the Hungarian and Polish discussants (i.e. from countries where the level of social trust is low). Representatives of British aid agencies did not mention such problems, underlining that initiatives for getting 'local resources' for aid activities are undertaken and carried out.

I have already mentioned that those agencies which focus their aid towards rural areas are often small organisations with limited human and financial resources and are generally less experienced. Agencies connected with large urban centres where they function, have an advantage over them. They generally have a highlyqualified, experienced team of professionals, considerablefinancial and other resources enabling them to carry out programmes (equipment, access to information, contacts etc.). This leads to the centralisation of programmes (emphasised by the Hungarian respondents). That happens with programmes getting financial resources through competition, generally won by institutions connected with large urban agglomerations. It is paradoxical that groups most threatened with exclusion and social marginalisation or actually experiencing it receive help which is limited. Geographic marginalisation is closely connected with social marginalisation and exclusion which often leads to dual - social marginalisation ${ }^{10}$.

Aid agencies functioning in rural areas struggle with restrictions resulting from the rural nature of the labour market which is small and saturated. What it has to offer is not only numerically limited but also lacking in variety. So when the aid agencies adapt their projects to the requirements of the labour market they have little room for manoeuvre, the consequence being an

${ }^{9}$ I base the point about low social trust on the results of the 2nd European Research on Quality of Life in 2009, http://www.eurofound.europa.eu/publications/htmlfiles/ef0902.htm [22.11.2009] pp. 54-56.

${ }^{10}$ It is here worth referring to the observations of Hungarian respondents who noticed the many aspects of marginalisation and social exclusion, underlining the significant variables - age and ethnic origin. At a distance from large urban centres, rural areas in Hungary are mainly inhabited by elderly people (the young having gone away to town) and ethnic minorities - mainly Roma, daily experiencing various forms of social discrimination. Due to the centralisation of programmes, the help they are given is limited, their marginalisation and exclusion are so much greater (dual - social and geographical marginalisation). 
incomplete educational proposal for the inhabitants of rural areas. It is also worth drawing attention to another problem resulting from those restrictions. It is very difficult to create an educational programme which would include both the requirements of the rural labour market and clients' expectations (potential and actual recipients of training, courses and apprenticeship). This leads to the omission of the view of the marginalised, the excluded and those exposed to marginalisation and social exclusion, mainly adapting the activity to the requirements of the rural labour market ${ }^{11}$. The marginalised, excluded and exposed to social exclusion are absent at decision making level - both during the construction of a framework, the project structure and delivery agencies as well as the level of implementation agencies. Their views and expectations are hardly taken into consideration. This situation is further complicated by the fact that although a so-called recognition of educational needs is carried out, it is generally limited to pointing out those needs (clients are questioned about their educational requirements), without understanding or verification ${ }^{12}$. The clients' presence in delivery agencies should not be based on their physical participation in training, courses etc. or simply be a question of identifying their needs but should also involve understanding those needs and understanding the recipients (recognising their specific nature) ${ }^{13}$. It seems that a successful inclusive policy is one that guarantees the widely understood presence of its recipients.

When embarking on the question of restrictions in the nature of the rural labour market mention should also be made that a considerable difficulty in the aid activity of the researched agencies is the reluctant attitude of rural employers towards training and courses. This problem was raised by respondents from Hungary and Poland. It is difficult to convince employers in the countryside about the advantages training and improved qualifications

11 This adaptation is further restricted by the already mentioned programme inflexibility.

${ }_{12}$ More about this in section 3.3 during the question about low or lacking awareness of educational needs and expectations in target groups.

${ }_{13}$ Among the unemployed Hungarian rural inhabitants there is a difference between the nature of the young unemployed, the elderly unemployed and the unemployed Roma. The poorly educated young rural inhabitants in Great Britain who are threatened with social marginalisation and exclusion have a different situation to teenage mothers in the countryside (this problem has been raised as a serious issue in that country). Young inhabitants in poststate farm areas in Poland have different requirements to young rural inhabitants not living in areas which were former state farms. 
of their employees can bring to their businesses, particularly when they need time off from their duties to attend courses.

\subsection{Problems Connected with the Clients of Aid Agencies}

The effectiveness of inclusive policy where clients are either absent or their presence minimal, is also limited by difficulties in reaching the clients. This mainly affects those who are excluded from the main stream of social life the complexity of social exclusion is partly determined by individuals and entire social groups finding themselves in social isolation which it is hard to break through. Not only has society turned away from them but they have consequently turned away from society. A serious problem which is rarely noticed by those connected with inclusive policy and practice is the selfmarginalisation and cultivated helplessness of the excluded. Activities aiming at the education and professional re-education of clients - trying to include them into social life (cultural, political, economic) may be ineffective when having to deal with cultivated helplessness. Social exclusion is a phenomenon of both social and psychological exclusion and often means self-marginalisation at the root of which lies the above-mentioned cultivated helplessness. Those who participated in focused group interviews indicated that their beneficiaries were often motivated to change their own social standing. Perhaps those clients who lasted out until the end of courses or training were neither excluded nor exposed to exclusion. This point is based on the assumption that transgression, going beyond the structural and symbolic restrictions of social standing, requires individuals to have a specific disposition, a constructive attitude towards their own fate, success, and belief in the possibility of creating it. Simply desiring another world, another life, the need for emancipation etc. is insufficient for becoming included. Action, creation and consistency are essential. That becomes all the more bothersome considering the obstacles mentioned by the respondents in aid activity which they described as low client motivation. Many participants of courses and training drop out of education (mentioned particularly by the respondents from Poland). The discussants noticed that limiting social exclusion through education largely depends on the motivation of those making use of that education. A view even appeared that the contents and form of the training or course is of no significance as regards the effectiveness, since what is decisive is the kind of person who completes a given course. Course participants have various attitudes towards the educational process - a varying level of interest, attendance and discipline. 
For example, in Great Britain the respondents underlined that it is difficult to convince potential clients (target groups) as regards different educational proposals because in their opinion there is no direct link between course or training participation and an improvement in their standard of living or income growth. Involvement and motivation are low due to a low faith in the added value, benefit from completing a course or training (converting that into money). Moreover, as the social welfare system in Great Britain the purpose of which is to overcome poverty is effective, so on the other hand, to many beneficiaries it is a trap - a benefit trap resulting in low motivation for change, or activity for those people who fall into it, often provoking in them the syndrome of cultivated helplessness.

Some thought should be given to 'low client motivation' and what lies at the bottom of it. Is it the social welfare system, self-marginalisation or perhaps the educational proposal which appears unattractive to its potential recipients, inadequate not only with regard to their expectations but also to the dynamically changing labour market? Considering the difficulties and barriers in the activity of aid agencies, emerging from the specificity of that activity, I put forward a motion about omitting the opinion of the marginalised, excluded, exposed to marginalisation and social exclusion in rural areas. I indicated that they are either partly or totally absent from both decision and implementation level in aid programmes which are aimed at them. When writing about them partly present I mean those activities where attempts are made to diagnose the educational needs of target groups or to enter into dialogue with them. Recognising the educational needs mainly takes place by talking to the clients and through questionnaires. Few institutions make use of external expert evaluations and tests ${ }^{14}$. Questionnaires and interviews with clients are a useful method, however, the fact that this is often the only method used by institutions raises doubts on which they base their educational proposals aimed at the marginalised, or exposed to marginalisation in rural areas. Are the needs of target groups identified in a reliable manner? Are the education programmes which are constructed according to the clients' requirements effective? In practice such actions do not seem successful. Consideration must here be given to the fact that in a situation of poor or non-existent awareness of one's own educational needs and expectations in target groups, this being one

14 This motion is backed up with the results of survey research which was part of the research project "The impact of Lifelong Learning policies on the inclusion of vulnerable groups". 
of the aspects of the nature of those groups (I have written about exclusion and misunderstanding earlier), it is very difficult to 'discover' them. Diagnosing so-called educational needs by means of questionnaires or in conversation is difficult.

\section{Conclusion}

Approaching the end of this article the aim of which was the recognition and indication of difficulties, limitations in the implementation of inclusive policy based on lifelong learning in rural areas, it is important to be aware of the limitations of my investigations. My deliberations were based on the analysis of problems and barriers in the aid activity of the researched agencies without quoting or investigating their successes. There are many. I mentioned at the beginning that the majority of representatives of the researched agencies give themselves a good evaluation - the majority of respondents believe in the effectiveness of their educational activity. I underlined that that conviction may be interpreted as a functional 'defence' of the principle organising the existence and activity of aid agencies. Aid agencies are often expected to evaluate their own activity - it is therefore, not difficult to imagine the consequences of an evaluation which contains problems, restrictions or facts identified as a failure. It is far safer to diagnose successes. The success of aid activity is proof of the effectiveness of an institution and thus legitimises its activity and raison dêtre. Funds are allocated to such institutions and they are entrusted with the running of programmes. Hence diagnosing successes, overlooking restrictions or failures is highly functional. It leads to a dangerous situation in which emerging problems, restrictions which may and often do lead to setbacks get ignored. This in turn leads to a vicious circle - such an evaluation is a sign to decision makers that there is no need for change and that the system is perfect. The institutions which admit successes, thereby overlooking the limitations and barriers appear to satisfy the expectations of sponsors who decide how financial resources are distributed for aid activity. However, in reality there are several difficulties, barriers limiting activity, effectiveness of aid agencies particularly those whose activity focuses on rural areas. It is interesting that during the interview these problems were articulated by representatives of institutions who seem to 'forget' about them during evaluation. It seems that aid agencies function on two levels - the official, slightly embellished one and the everyday, less pleasant one where success is far less attainable. The vicious 
circle mechanism sets in motion a dangerous illusion. I would call it the good work illusion, which is reinforced by other kinds of illusion: the illusion concerning those who have been included, the illusion of the kind 'we know what they need' and the illusion of statistical data ${ }^{15}$. An illusion affecting those who have been included is based on research results, the analysis of which provides doubts connected with the question about who has in fact been included - were those people who lasted until the end of courses, training and apprenticeship excluded or exposed to exclusion?. Both types of illusion are supplemented by another type of illusion: 'we know what they need' based on the assumption that the excluded and exposed to exclusion should be provided with such professional skills which will lead to finding employment. As I have already mentioned it is a deceptive conviction that finding employment means inclusion. Doubts are also raised by the 'knowledge' based on conversations with clients and by interviewing them, this being the most frequent method of acquiring information about the recipients' educational needs. It is very difficult to examine the influence of a concrete course, training or apprenticeship on the process of social integration, and to determine that inclusion was the result of appropriate education. That is why many doubts are raised by statistical data which are used by institutions dealing with inclusive policy. How can it be stated on that basis that the activity leads to the social integration of the marginalised? It seems that the short period of time between the beneficiary completing a course, training etc. and acquiring employment, does not allow for adjudicating about social inclusion. It is interesting and typical that during discussions the representatives of institutions of interest to us raised doubts in the credibility of data which they use daily when evaluating the results of their work (the Polish discussants, although this was a delicate topic and unwillingly discussed similar voices were raised during the discussion in Hungary). The participants of focused group interviews in the mentioned countries underlined that in research aiming at evaluating their aid activity, they have difficulty interpreting the results. They considered the questionnaires filled in by course and training graduates with whom they managed to keep in touch after course completion as being unrepresentative. Those people have a positive attitude towards the institution due to which they have raised or obtained professional

${ }^{15}$ I wrote more about this in an article entitled „Inclusion or illusion? About lifelong learning as an opportunity of integration for the marginalised" [Pluskota-Lewandowska, A. 2008, pp. 185-199] 
qualifications, which, according to the representatives of those institutions does not allow to consider the research results as being reliable. Moreover, that research is often the very fact of aid agencies helping them find work and then being informed that they have found work. It sometimes happens that the drop in number of unemployed gets treated as a confirmation of the effectiveness of educational activities conducted by researched institutions, whereas stability and growth in unemployment are clarified by the bad situation on the labour market (as well as the poor economic climate). That is how I assumed the point about the illusion of statistical data.

Illusion is not only expected and consequently created but also, which seems most dangerous in results, included into the realm of aid activities. Hence I raise the point about illusion of inclusion as well as inclusion of illusion.

Is the idea of using lifelong learning for the social integration of the excluded and marginalised as well as those exposed to marginalisation and social exclusion of no avail or are the expectations connected with lifelong learning perhaps unreasonable? What is it that makes it difficult to achieve in practice? Why is it that in spite of those engaged in the implementation of that idea in rural areas being aware of the difficulties and restrictions in their aid activity, can they not effectively prevent and solve them? Considering the findings made in this research, I am inclined to think that the cause of this lies in the incapacity of getting out of the vicious circle which is set in motion by the above mentioned illusion (its several aspects). The illusion of inclusion and the inclusion of illusion 'produced' by the problems, policy restrictions and inclusive activity described in this article.

Nevertheless however, bearing in mind that many of the aid agencies using education, function within the realm of a dangerous illusion, I am far from undermining the possibilities, potential and very idea of lifelong learning. It seems that in this context actions aiming towards a change in inclusive policy, particularly in the actual construction of aid projects are becoming essential ${ }^{16}$.

16 The construction of aid projects and programmes have several restrictions which contribute to the emergence of difficulties in implementing inclusive policy. 


\section{References}

The $2^{\text {nd }}$ European Quality of Life Test (2009). Retrieved 22 November 2009 on the World Wide Web: http://www.eurofound.europa.eu/publications/htmlfiles/ ef0902.html

Europa, 2003 European Commission: Policy Areas: Lifelong Learning, What is Lifelong Learning? Retrieved 2 October 2003 on the World Wide Web: http:// europea.eu.int/comm/education/policies/lli/life/what_islll_en.html

The Country Action Plan for Social Integration in 2004-2006. Retrieved 20 October 2007 on the World Wide Web: http://www.mps.gov.pl/integracja/index.php? mleft $=4 \&$ submenu +4

National Social Integration Strategy. 20 October 2007 http://www.mps.gov.pl./ integracja/index.php? $\mathrm{mleft}=6$

Papageorgiu, F. 2008 The Impact of Lifelong Learning Policies on the Inclusion of Vulnerable Groups. Eastern European Countryside. No 14: 61-79.

Papageourgiu F. 2007 Learn to Coexist - Learn to Thrive: The Impact of Lifelong Learning Policies on the Inclusion of Vulnerable Groups, Athens: EURACADEMY Association.

Pluskota-Lewandowska A. 2008 Inclusion or Illusion? About Lifelong Learning as an Opportunity of Integration for the Marginalised. In Wachowiak, A. (Ed.), Sociology as Social Therapy (pp. 185-199), Zielona Góra: University Press.

The Impact of Lifelong Learning Policies on the Inclusion of Vulnerable Groups, Survey Reports Hungary. Retrieved 15 October 2008 on the World Wide Web: http://www.lll4inclusion.net

The Impact of Lifelong Learning Policies on the Inclusion of Vulnerable Groups, Survey Reports Poland. Retrieved 15 October 2008 on the World Wide Web: http://www.lll4inclusion.net

The Impact of Lifelong Learning Policies on the Inclusion of Vulnerable Groups, Survey Reports United Kingdom. Retrieved 15 October 2008 on the World Wide Web: http://www.lll4inclusion.net 